\title{
Trabectedin arrests a doxorubicin-resistant PDGFRA-activated liposarcoma patient- derived orthotopic xenograft (PDOX) nude mouse model
}

\author{
Tasuku Kiyuna ${ }^{1,2,3}$, Yasunori Tome ${ }^{3 *}$, Takashi Murakami ${ }^{1,2}$, Kei Kawaguchi $^{1,2}$, Kentaro Igarashi $^{1,2}$, Kentaro Miyake $^{1,2}$, \\ Masuyo Miyake ${ }^{1,2}$, Yunfeng Li ${ }^{5}$, Scott D. Nelson ${ }^{5}$, Sarah M. Dry ${ }^{5}$, Arun S. Singh ${ }^{4}$, Tara A. Russell, Irmina Elliott ${ }^{6}$, \\ Shree Ram Singh ${ }^{7^{*}} \mathbb{D}$, Fuminori Kanaya ${ }^{3}$, Fritz C. Eilber ${ }^{6^{*}}$ and Robert M. Hoffman ${ }^{1,2^{*}}$
}

\begin{abstract}
Background: Pleomorphic liposarcoma (PLPS) is a rare, heterogeneous and an aggressive variant of liposarcoma. Therefore, individualized therapy is urgently needed. Our recent reports suggest that trabectedin (TRAB) is effective against several patient-derived orthotopic xenograft (PDOX) mouse models. Here, we compared the efficacy of first-line therapy, doxorubicin (DOX), and TRAB in a platelet-derived growth factor receptor-a (PDGFRA)-amplified PLPS.

Methods: We used a fresh sample of PLPS tumor derived from a 68-year-old male patient diagnosed with a recurrent PLPS. Subcutaneous implantation of tumor tissue was performed in a nude mouse. After three weeks of implantation, tumor tissues were isolated and cut into small pieces. To match the patient a PDGFRA-amplified PLPS PDOX was created in the biceps femoris of nude mice. Mice were randomized into three groups: Group 1 (G1), control (untreated); Group 2 (G2), DOX-treated; Group 3 (G3), TRAB-treated. Measurement was done twice a week for tumor width, length, and mouse body weight.

Results: The PLPS PDOX showed resistance towards DOX. However, TRAB could arrest the PLPS ( $p<0.05$ compared to control; $p<0.05$ compared to DOX) without any significant changes in body-weight.

Conclusions: The data presented here suggest that for the individual patient the PLPS PDOX model could specifically distinguish both effective and ineffective drugs. This is especially crucial for PLPS because effective first-line therapy is harder to establish if it is not individualized.
\end{abstract}

Keywords: Liposarcoma, Patient-derived orthotopic xenograft, PDOX, PDGFRA amplification, Trabectedin, Precision medicine

\section{Background}

Pleomorphic liposarcoma (PLPS), a type of sarcoma, is a rare and an aggressive variant of liposarcoma. PLPS is a recalcitrant disease. Patients with PLPS develop an elevated level of local recurrence and distant metastasis with poor prognosis [1]. PLPS consists of approximately

\footnotetext{
*Correspondence: yash_toume@hotmail.com; singhshr@mail.nih.gov; fceilber@mednet.ucla.edu; all@anticancer.com

${ }^{3}$ Department of Orthopedic Surgery, Graduate School of Medicine, University of the Ryukyus, Okinawa, Japan

${ }^{7}$ Basic Research Laboratory, National Cancer Institute, Frederick, MD, USA

${ }^{6}$ Division of Surgical Oncology, University of California, Los Angeles, CA, USA

'AntiCancer Inc., San Diego, CA, USA

Full list of author information is available at the end of the article
}

$10 \%$ of liposarcomas. PLPS has been investigated in soft tissue sarcomas (STS) such as head and neck sarcoma as well as bone sarcoma [2,3] and has been demonstrated in patients of all ages [4-7]. Wang et al. [8] reported 6 PLPS cases out of a total 89 liposarcoma cases between 2003 and 2017. All 6 patients underwent complete tumor resection and only one patient received chemotherapy with ifosfamide and epirubicin [8]. A primary PLPS in an 18-year-old male in the metaphysis of the left tibia was reported by Tiemeier et al. [3]. The patient was treated with methotrexate, doxorubicin and cisplatinum (MAP). Pathology results demonstrated extensive ( $>95 \%$ ) tumor necrosis due to neoadjuvant chemotherapy.

(c) The Author(s). 2018 Open Access This article is distributed under the terms of the Creative Commons Attribution 4.0 International License (http://creativecommons.org/licenses/by/4.0/), which permits unrestricted use, distribution, and reproduction in any medium, provided you give appropriate credit to the original author(s) and the source, provide a link to the Creative Commons license, and indicate if changes were made. The Creative Commons Public Domain Dedication waiver (http://creativecommons.org/publicdomain/zero/1.0/) applies to the data made available in this article, unless otherwise stated. 
Chemotherapy and post-operative results after 12 months showed no sign of recurrence [3]. Yan et al. [9] have shown an 81-year-old Chinese woman with advanced PLPS who was treated with apatinib after failure of chemotherapy had good efficacy and low toxicity. Apatinib was also used in patients with advanced sarcoma [10]. In search of molecular biomarkers, Ghadimi et al. [11] tested 155 PLPS patients using tissue microarrays, and identified several potential therapeutic targets [11].

Surgical resection at present is the only effective therapeutic option for localized PLPS. In addition, radiation and chemotherapy are largely ineffective for advanced stages of this disease [11-14]. Thus, for patients, personalised and targeted therapy is necessary to overcome the metastatic PLPS.

To accomplish this goal, our laboratory has developed the patient-derived orthotopic xenograft (PDOX) nudemouse model for many tumor types [15-49]. Our PDOX model is advantageous compared to subcutaneous (s.c.)-transplanted patient-derived xenograft (PDX) models in various aspects $[50,51]$. In contrast to PDOX model, s.c.-transplanted PDX models fail to develop an advanced tumor stage and cannot retain the original disease pattern generally observed in patients, PDOX models metastasize because tumor tissues are engrafted in the orthotopic sites of origin [50-52]. Importantly, the metastasic form of PDOX model matches the patient. Even though high technical skill, time commitment, and more costly procedures are needed for the PDOX models compared to traditional subcutaneous PDX models, PDOX models are important for individual patients and can be used as a powerful tool in preclinical modelling [50-52].

Trabectedin (TRAB) for patients with metastatic liposarcoma has been approved by the FDA [53] and is marketed by Janssen Pharma as Yondelis [54]. TRAB is a tetrahydroisoquinoline alkaloid compound, derived from the Carribean sea tunicate, Ecteinascidia turbinate [7, 55]. TRAB is a promising antitumor agent [56-59]. Nteli et al. [60] reported a durable response to TRAB in a patient with high-grade uterine leiomyosarcoma. It was reported that cells lacking a homologous recombination system were more sensitive to TRAB [61]. Subsequently, Larsen et al. [62] found that an interaction between a minor groove (DNA), and transcription factors, or DNA-repair molecules such as BRCA1, with TRAB alters the cell cycle and induces cell death. TRAB also showed anti-inflammatory and immunomodulatory properties [62]. Several studies reported that a haplotype in the $B R C A 1$ gene could be utilized as a marker for predicting TRAB effectiveness in patients with STS [63-65]. Angarita et al. [66] reported some efficacy of TRAB to advanced STS patients who did not respond to first-line chemotherapy.
Recently, we showed that TRAB is efficacious on several PDOX models [25, 30, 32, 67]. Here, we tested the efficacy of first-line chemotherapy, doxorubicin (DOX) [42], and TRAB in a PDGFRA-amplified [68] PLPS PDOX model [69].

\section{Methods \\ Mice}

In the present study, athymic $n u / n u$ nude mice, between 4 and 6 weeks old, were utilised [69]. Experimental procedures and data collection were done as per as our previous publications [22, 24, 30, 32, 38, 47, 69, 70]. Mouse housing, feeding, surgical processes and imaging were conducted as described in our previous publications [22, 24, 30, 32, 38, $47,69,70]$. The mice were humanely sacrificed as described in our previous publications [22, 24, 30, 32, 38, 47, 69, 70]. The mouse investigations presented here were done using an AntiCancer, Inc. Institutional Animal Care and Use Committee (IACUC)-protocol specifically approved for this study as previously described [47] and as per as principles and procedures provided in the National Institute of Health (NIH) Guide for the Care and Use of Animals under Assurance Number A3873-1 [47].

\section{Patient-derived PLPS tumor}

In this study, we used a PLPS tumor derived from a 68-year-old male patient diagnosed with a recurrent PLPS, which has been described in our previous publication [69]. Details of surgical resection and chemotherapy given to this patient have been previously described [69].

\section{Establishing the PLPS PDOX model using the surgical orthotopic implantation (SOI) technique}

PLPS sample collection from the patient, performing subcutaneous implantation in nude mice, harvesting tumors from the mice, creating a space at the orthotopic site in the biceps femoris to insert tumor fragments in the mice and to establish the PDOX model and wound-closure procedures have been described in detail in our previous publications [22, 24, 30, 32, 38, 47, 69].

\section{Treatment regime}

All treatment procedures and data collection were done as previously reported [22, 24, 30, 32, 38, 47]. PLPS PDOX mouse models were randomized into three groups as previously described [69]: Group 1 (G1), control (untreated); Group 2 (G2), DOX-treated (3 mg/kg, i.v., weekly for 2 weeks); Group 3 (G3), TRAB-treated ( $0.15 \mathrm{mg} / \mathrm{kg}$, i.v., weekly for 2 weeks). In each group, 7 mice were used. Measurement of tumor width, length, and mouse body weight was done as described in our previous publications [22, 24, 30, 32, 38, 47, 69]. The doses and treatment time were selected from our previous PDOX studies [22, 24, 30, 32, 38, 47, 69]. DOX was selected because it is first-line therapy for PLPS. 


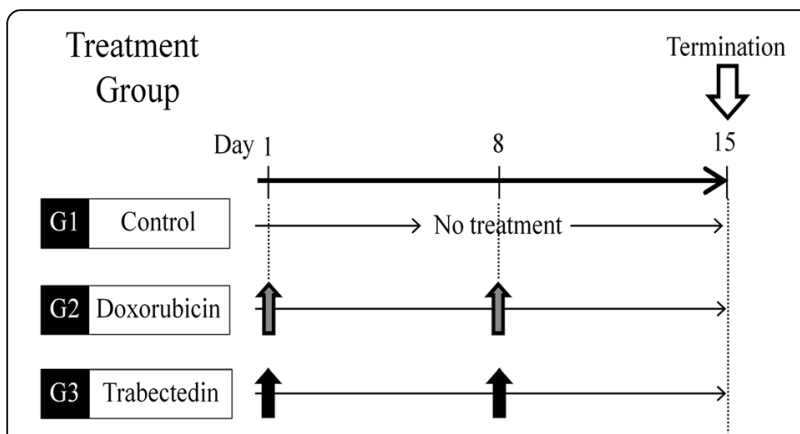

Fig. 1 Treatment protocol and quantitative drug efficacy. Treatment protocol. G1: untreated control $(n=7)$; G2: treated with doxorubicin (DOX) (3 mg/kg, i.v., weekly, 2 weeks, $n=7)$; Group 3, treated with trabectedin (TRAB) $(0.15 \mathrm{mg} / \mathrm{kg}$, i.v., weekly, 2 weeks, $n=7)$. All treated mice were sacrificed on termination day-15, and tumors were resected for further histological evaluation

A formula to calculate the tumor volume has been previously described [69]. All data are presented in the results section as mean $\pm \mathrm{SD}$. Drug treatment was started only when the tumor volume attained $50 \mathrm{~mm}^{3}$ [69]. The tumor volume ratio and the actual body weight was measured as defined in our previous publications $[22,24,30,32,38,47,69]$. Mice were sacrificed on day 15 in each drug-treatment group and tumors were resected for further histological analysis as described in our previous publication [69].

\section{Histopathological evaluation}

All histological procedures, data collection, and analysis were done as previously reported [22, $24,30,32,38,47,71]$.

\section{Statistical analysis}

All statistical analyses were done using JMP pro version 12 [69]. The relative tumor volumes and relative body weight of the mice are presented as mean \pm SD [69]. The Mann-Whitney $U$ test was used to confirm the significant differences for continuous variables. $P$ values of less than 0.05 were regarded as statistically significant.

\section{Results}

\section{Drug efficacy in the PLPS PDOX mouse model}

To test the efficacy of each drug in the PLPS PDOX mouse model, two weeks following orthotopic implantation, mice with tumors were randomized into three groups to initiate treatment (Fig. 1). We found that in the control group (G1-untreated) tumors grew more than five times larger by day 14 compared to day 0 (tumor- volume ratio $=5.61 \pm 2.14$ ). In the DOX-treated group (G2), on day 14, we could not observe a significant reduction of tumor growth [69] compared to the control group (tumor-volume ratio $=4.33 \pm 2.57, p=$ $0.927)$. In contrast, TRAB (G3) treatment showed significant tumor-growth inhibition on day 14 (tumor-volume ratio $=1.60 \pm 1.13, p=0.0032$ compared to the control). In addition, on day 14, TRAB treatment also resulted in more suppression of tumor growth than DOX treatment $(p=0.0092)$ (Fig. 2). It took two weeks for the tumor to initially grow to $50 \mathrm{~mm}^{3}$. The tumor volumes at the end of the experiment were: untreated control, $621 \pm 297 \mathrm{~mm}^{3}$; DOX, $507 \pm 191 \mathrm{~mm}^{3}$; TRAB, $159 \pm 95 \mathrm{~mm}^{3}$ (Fig. 3a).

Figure $3 \mathrm{~b}$ shows representative images of tumors harvested from the biceps femoris at the termination point on day 15. The control group had the largest tumors and the TRAB groups had the smallest tumors (Fig. 3b).

\section{Effect of drug treatment on body weight}

We measured the mouse body weight pre-treatment (before) as well as post-treatment (after). We did not find

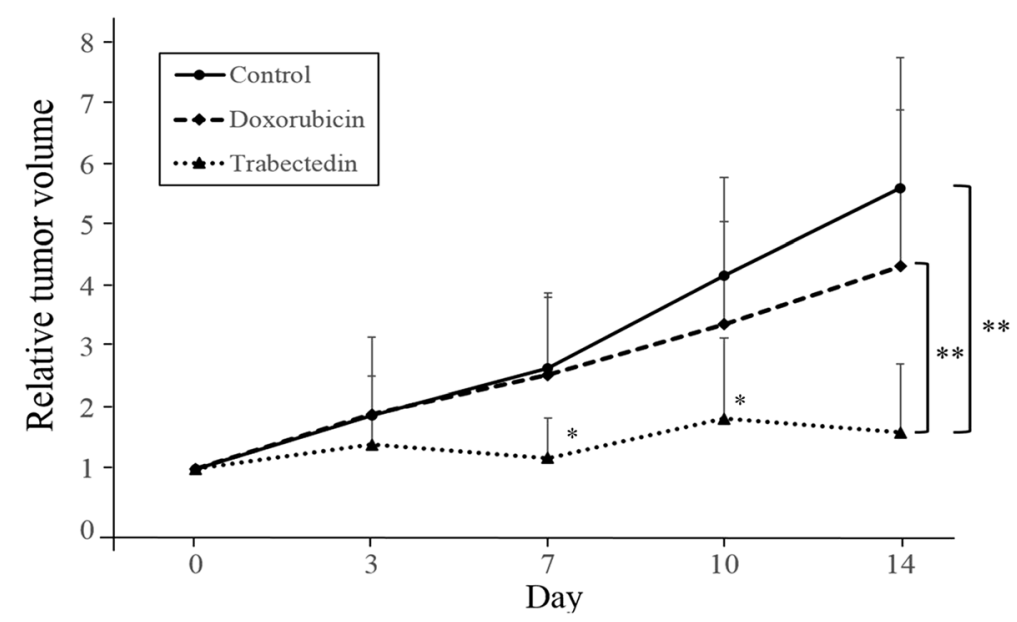

Fig. 2 Line graphs show relative tumor volume (tumor at any time point relative to day 0 ). ${ }^{*} p<0.05,{ }^{* *} p<0.01$, Error bars: $\pm S D$ 

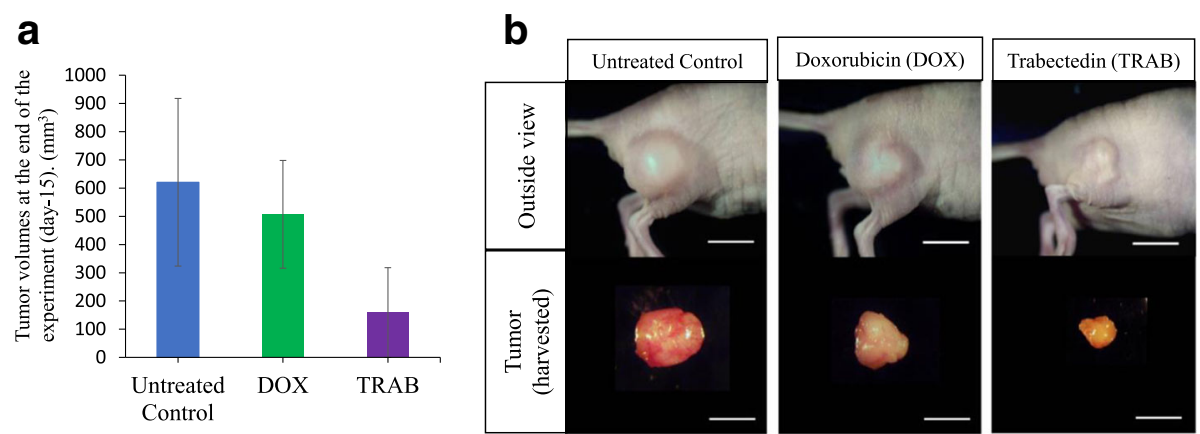

Fig. 3 a Tumor volumes at the end of the experiment (day-15). b: Macro tumor images after treatment. All treated mice were sacrificed on day-15, and tumors were resected for further histological evaluation. Images are representative of tumors harvested after orthotopic growth in the biceps femoris. Scale bar: $10 \mathrm{~mm}$

any significant differences in the body weight between any treatment group (Fig. 4).

\section{Effect of drug treatment on tumor histology}

We analysed the tumor histology in the untreated (control) and treated tumors (treated with DOX or TRAB). Photomicroscopy results showed that both the original patient tumor and untreated control-group tumor had enlarged and hyperchromatic nuclei with cytoplasmic vacuoles that are usual in PLPS [69] (Fig. 5a and b). Further, the untreated (control) PDOX tumor exhibits normal and viable cancer cells in nearly all areas [69] (Fig. 4b). In contrast to the DOX-treated tumor that did not show necrotic areas (Fig. $5 \mathrm{c}$ ), the TRAB-treated tumor (Fig. 5d) shows extensive necrosis (Fig. 5c).

\section{Discussion}

First-line systemic therapy for PLPS with an anthracycline, such as a DOX-containing regimen, has a low response rate [72] consistent with our results presented here. We found that the PLPS PDOX showed resistance to first-line therapy DOX, which is similar to our previous study [69]. In contrast, the PLPS PDOX was arrested by TRAB. This suggests that PLPS PDOX model could specifically recognize both effective and ineffective drugs for each patient [69].

TRAB is a novel marine-derived alkaloid [7, 73]. It attaches covalently to the DNA minor groove and interacts with transcription factors [74]. Recently, Pignochino et al. [75] demonstrated TRAB and Poly [ADP-ribose] polymerase 1 (PARP1 1) inhibition synergism in sarcomas. Laroche et al. [76] tested the efficacy of a combination of

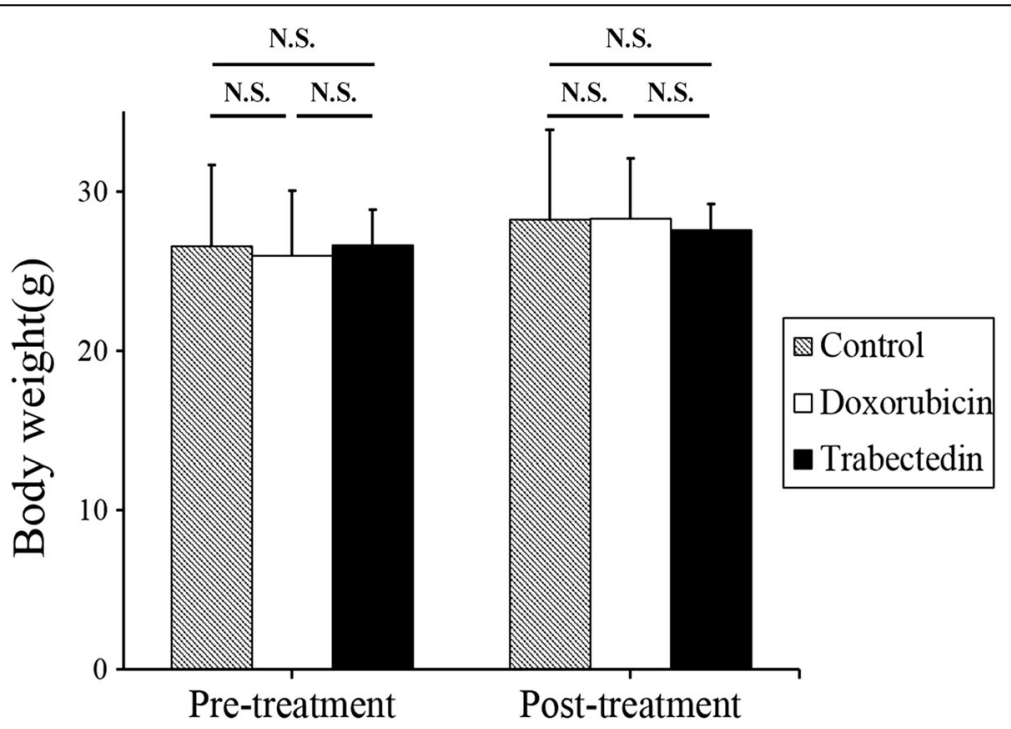

Fig. 4 Mouse body weight. Bar graphs show body weight of mice treated with each compound as well as the untreated control. Error bars: \pm SD. n.s.: not significant 

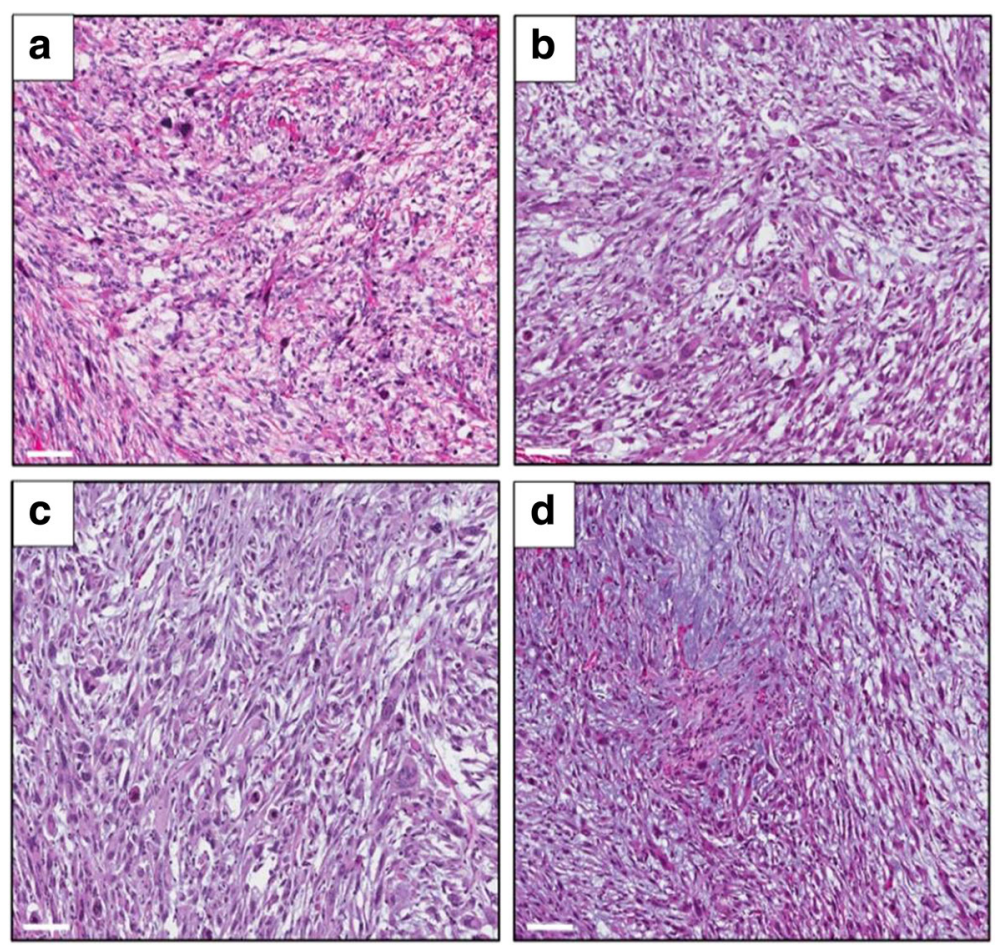

Fig. 5 Tumor histology. Hematoxylin and eosin (H\&E), a stained sections of tumors. a: original patient tumor; b: untreated control PDOX tumor; c: DOX-treated PDOX tumor; d: TRAB- treated PDOX tumor. Scale bars: $100 \mu \mathrm{m}$

TRAB and rucaparib on STS and found that they were also synergistic, enhanced apoptosis and blocked the cell cycle. In addition, these combinations were more effective than TRAB and rucaparib alone [76]. Further, they observed that the combination of these two drugs resulted in elevated $\gamma \mathrm{H} 2 \mathrm{AX}$ intranuclear accumulation, which is due to DNA-damage induction [76]. In vivo results further demonstrated that combining these two drugs significantly improved disease-free survival with massive tumor necrosis [77]. A few studies also showed that TRAB has anti-tumor and anti-inflammatory activities [77, 78] and can selectively lower monocytes, tumor-associated macrophages (TAM), and angiogenesis [77]. It has also been demonstrated that the therapeutic efficacy of TRAB in osteosarcoma is increased in combination with a PD-1-blocking antibody [79].

TRAB has been demonstrated as a therapeutic option in STS [56, 57, 80-86], recurrent ovarian cancer [87], metastatic breast cancer [88], solitary fibrous tumor (SFT)-PDXs [89], desmoplastic small round cell tumor [90], juvenile myelomonocytic leukaemia and chronic myelomonocytic leukaemia [91]. Recently, we reported that TRAB is efficacious on an osteosarcoma cisplatinum-resistant lung metastasis [67], a BRAF-V600E mutated melanoma [30, 32] and a gemcitabine (GEM)-resistant pancreatic cancer [25].

Here we showed that TRAB was highly effective against a PDOX model of PLPS with a PDGFRA activating mutation [68] in comparison to DOX. The above results together suggest the improved clinical prospect of PLPS and the importance of individualized therapy with PDOX models [70]. Experiments will be performed in the future to compare TRAB with other first-line therapies of PLPS such as docetaxel and ifosfamide. Whether TRAB will be effective against unresetable PLPS is an experimental question since drug sensitivity is highly specific for each patient. It will be possible to answer this question in the future with a PDOX model derived from a core-needle biopsy.

\section{Conclusions}

Our results suggest that the PLPS PDOX model [69] can precisely distinguish both efficacious and non-efficacious drugs for each patient. These results are crucial for PLPS, which is a heterogeneous group, where effective first-line therapy is difficult to establish if it is not individualized [69].

\section{Acknowledgements}

This manuscript is dedicated to the memory of Dr. A.R. Moossa and Dr. Sun Lee.

Availability of data and materials

The datasets used and/or analyzed during the current study are available from the corresponding author on reasonable request. 


\section{Authors' contributions}

TK and RMH was involved in study conception and design. TK, YT, TM, KK, KI, KM, MM, YL, SDN, SMD, ASS, TAR, IE, SRS, FK, FCE, and RMH were involved in analysis and interpretation of data. TK and RMH were involved in drafting of manuscript. SRS was involved in critical revision of manuscript. All authors read and approved the final manuscript.

\section{Ethics approval and consent to participate}

Written informed consent was obtained from the patient as part of a University of California, Los Angeles (UCLA) Institutional Review Board (IRB\#10-001857) approved protocol. Written informed consent was obtained from the patient for publication of the study. All mice investigations were done with an AntiCancer, Inc. Institutional Animal Care and Use Committee (IACUC)-protocol mainly approved for this study and in correspondence with the principals and procedures outlined in the National Institute of Health $(\mathrm{NIH})$ Guide for the Care and Use of Animals under Assurance Number A3873-1.

\section{Consent for publication}

Written informed consent was obtained from the patient for publication of the study.

\section{Competing interests}

The authors declare that they have no competing interests.

\section{Publisher's Note}

Springer Nature remains neutral with regard to jurisdictional claims in published maps and institutional affiliations.

\section{Author details}

${ }^{1}$ AntiCancer Inc., San Diego, CA, USA. ${ }^{2}$ Department of Surgery, University of California, San Diego, CA, USA. ${ }^{3}$ Department of Orthopedic Surgery, Graduate School of Medicine, University of the Ryukyus, Okinawa, Japan. ${ }^{4}$ Division of Hematology-Oncology, University of California, Los Angeles, CA, USA. ${ }^{5}$ Department of Surgery, University of California, Los Angeles, CA, USA. ${ }^{6}$ Division of Surgical Oncology, University of California, Los Angeles, CA, USA. ${ }^{7}$ Basic Research Laboratory, National Cancer Institute, Frederick, MD, USA.

Received: 6 February 2018 Accepted: 30 July 2018

Published online: 20 August 2018

\section{References}

1. Manji GA, Schwartz GK. Managing Liposarcomas: cutting through the fat. J Oncol Pract. 2016;12(3):221-7.

2. Agarwal J, Kadakia S, Agaimy A, Ogadzanov A, Khorsandi A, Chai RL. Pleomorphic liposarcoma of the head and neck: presentation of two cases and literature review. Am J Otolaryngol. 2017;38(4):505-7.

3. Tiemeier GL, Brown JM, Pratap SE, McCarthy C, Kastrenopoulou A, Bradley K, Wilson S, Orosz Z, Gibbons CLMH, Oppermann U, Athanasou NA. Pleomorphic liposarcoma of bone: a rare primary malignant bone tumour. Clin Sarcoma Res. 2018:8:2.

4. Ahmed Z, Shah HU, Yaqoob N, et al. Pleomorphic liposarcoma in a ten year old child. J Pak Med Assoc. 2004;54:533-4.

5. Saeed M, Plett S, Kim GE, et al. Radiological-pathological correlation of pleomorphic liposarcoma of the anterior mediastinum in a 17-year-old girl. Pediatr Radiol. 2010;40(suppl 1):S68-70.

6. Rudzinski E, Mawn L, Kuttesch J, et al. Orbital pleomorphic liposarcoma in an eight-year-old boy. Pediatr Dev Pathol. 2011;14:339-44.

7. Tseng WW, Somaiah N, Lazar AJ, Lev DC. Pollock RE novel systemic therapies in advanced liposarcoma: a review of recent clinical trial results. Cancers (Basel). 2013;5(2):529-49.

8. Wang L, Luo R, Xiong Z, Xu J, Fang D. Pleomorphic liposarcoma: an analysis of 6 case reports and literature review. Medicine (Baltimore). 2018;97(8):e9986.

9. Yan P, Sun ML, Sun YP, Liu CY. Effective apatinib treatment of pleomorphic liposarcoma: a case report. Medicine (Baltimore). 2017;96(33):e7771.

10. Xie L, Guo W, Wang Y, Yan T, Ji T, Xu J. Apatinib for advanced sarcoma: results from multiple institutions' off-label use in China. BMC Cancer. 2018; 18(1):396.

11. Ghadimi MP, Liu P, Peng T, Bolshakov S, Young ED, Torres KE, Colombo C, Hoffman A, Broccoli D, Hornick JL, et al. Pleomorphic liposarcoma: clinical observations and molecular variables. Cancer. 2011;117:5359-69.
12. Gebhard S, Coindre JM, Michels JJ, et al. Pleomorphic liposarcoma: clinicopathologic, immunohistochemical, and follow-up analysis of 63 cases: a study from the French Federation of Cancer Centers Sarcoma Group. Am J Surg Pathol. 2002;26(2):601-16.

13. Hornick JL, Bosenberg MW, Mentzel T, McMenamin ME, Oliveira AM, Fletcher CD. Pleomorphic liposarcoma: Clinicopathologic analysis of 57 cases. Am J Surg Pathol. 2004;28:1257-67.

14. Guan Z, Yu X, Wang H, Wang H, Zhang J, Li G, Cao J, Teng L. Advances in the targeted therapy of liposarcoma. Onco Targets Ther. 2015;8:125-36.

15. Fu X, Le P, Hoffman RM. A metastatic orthotopic-transplant nude-mouse model of human patient breast cancer. Anticancer Res. 1993;13:901-4.

16. Fu X, Hoffman RM. Human ovarian carcinoma metastatic models constructed in nude mice by orthotopic transplantation of histologicallyintact patient specimens. Anticancer Res. 1993;13:283-6.

17. Wang X, Fu X, Hoffman RM. A new patient-like metastatic model of human lung cancer constructed orthotopically with intact tissue via thoracotomy in immunodeficient mice. Int J Cancer. 1992;51:992-5.

18. Hiroshima Y, Zhang Y, Zhang N, Maawy A, Mii S, Yamamoto M, Uehara F, Miwa S, Yano S, Murakami T, Momiyama M, Chishima T, Tanaka K, Ichikawa Y, Bouvet M, Murata T, Endo I, Hoffman RM. Establishment of a patient-derived orthotopic Xenograft (PDOX) model of HER-2-positive cervical cancer expressing the clinical metastatic pattern. PLoS One. 2015;10(2):e0117417.

19. Murakami T, Kiyuna T, Kawaguchi K, Igarashi K, Singh AS, Hiroshima $Y$, Zhang Y, Zhao M, Miyake K, Nelson SD, Dry SM, Li Y, DeLong JC, Lwin TM, Chishima T, Tanaka K, Bouvet M, Endo I, Eilber FC, Hoffman RM. The irony of highly-effective bacterial therapy of a patient-derived orthotopic xenograft (PDOX) model of Ewing's sarcoma, which was blocked by Ewing himself 80 years ago. Cell Cycle. 2017;16(11):1046-52.

20. Hiroshima Y, Maawy A, Metildi CA, et al. Successful fluorescence-guided surgery on human colon cancer patient-derived orthotopic xenograft mouse models using a fluorophore-conjugated anti-CEA antibody and a portable imaging system. J Laparoendosc Adv Surg Tech A. 2014;24:241-7.

21. Fu XY, Besterman JM, Monosov A, Hoffman RM. Models of human metastatic colon cancer in nude mice orthotopically constructed by using histologically intact patient specimens. Proc. Natl. Acad. Sci. U S A. 1991;88:9345-9.

22. Metildi CA, Kaushal S, Luiken GA, Talamini MA, Hoffman RM, Bouvet M. Fluorescently labeled chimeric anti-CEA antibody improves detection and resection of human colon cancer in a patient-derived orthotopic xenograft (PDOX) nude mouse model. J Surg Oncol. 2014;109:451-8.

23. Furukawa T, Kubota T, Watanabe M, Kitajima M, Hoffman RM. Orthotopic transplantation of histologically intact clinical specimens of stomach cancer to nude mice: correlation of metastatic sites in mouse and individual patient donors. Int J Cancer. 1993;53:608-12.

24. Fu X, Guadagni F, Hoffman RM. A metastatic nude-mouse model of human pancreatic cancer constructed orthotopically with histologically intact patient specimens. Proc. Natl. Acad. Sci. U S A. 1992;89:5645-9.

25. Kawaguchi K, Igarashi K, Murakami T, et al. MEK inhibitors cobimetinib and trametinib, regressed a gemcitabine-resistant pancreatic-cancer patientderived orthotopic xenograft (PDOX). Oncotarget. 2017;8:47490-6.

26. Hiroshima Y, Maawy A, Zhang Y, et al. Metastatic recurrence in a pancreatic cancer patient derived orthotopic xenograft (PDOX) nude mouse model is inhibited by neoadjuvant chemotherapy in combination with fluorescenceguided surgery with an anti-CA 19-9-conjugated fluorophore. PLoS One. 2014;9:e114310

27. Hiroshima Y, Maawy AA, Katz MH, Fleming JB, Bouvet M, Endo I, Hoffman RM. Selective efficacy of zoledronic acid on metastasis in a patient-derived orthotopic xenograph (PDOX) nude-mouse model of human pancreatic cancer. J Surg Oncol. 2015;111(3):311-5.

28. Hiroshima Y, Zhang Y, Murakami T, Maawy A, Miwa S, Yamamoto M, Yano S, Sato S, Momiyama M, Mori R, Matsuyama R, Chishima T, Tanaka K, Ichikawa Y, Bouvet M, Endo I, Zhao M, Hoffman RM. Efficacy of tumor-targeting Salmonella typhimurium A1- R in combination with anti-angiogenesis therapy on a pancreatic cancer patient-derived orthotopic xenograft (PDOX) and cell line mouse models. Oncotarget. 2014;5(23):12346-57.

29. Yamamoto M, Zhao M, Hiroshima Y, et al. Efficacy of tumor-targeting Salmonella A1-R on a melanoma patient-derived Orthotopic Xenograft (PDOX) nude-mouse model. PLoS One. 2016;11:e0160882.

30. Kawaguchi K, Murakami T, Chmielowski B, et al. Vemurafenib-resistant BRAFV600E-mutated melanoma is regressed by MEK-targeting drug trametinib, but not cobimetinib in a patient-derived orthotopic xenograft (PDOX) mouse model. Oncotarget. 2016;7:71737-43. 
31. Kawaguchi K, Igarashi K, Murakami T, et al. Salmonella typhimurium A1-R targeting of a chemotherapy resistant BRAF-V600E melanoma in a patientderived orthotopic xenograft (PDOX) model is enhanced in combination with either vemurafenib or temozlomide. Cell Cycle. 2017;16:1288-94.

32. Kawaguchi K, Igarashi K, Murakami T, et al. Tumor-targeting Salmonella typhimurium A1-R sensitizes melanoma with a BRAF-V600E mutation to Vemurafenib in a patient-derived Orthotopic Xenograft (PDOX) nude mouse model. J Cell Biochem. 2017;18:2314-231.

33. Kawaguchi K, Igarashi K, Li S, et al. Combination treatment with recombinant methioninase enables temozolomide to arrest a BRAF V600E melanoma in a patient-derived orthotopic xenograft (PDOX) mouse model. Oncotarget. 2017;8:85516-25.

34. Kawaguchi K, Igarashi K, Murakami T, et al. Tumor-targeting Salmonella typhimurium A1-R combined with temozolomide regresses malignant melanoma with a BRAF-V600E mutation in a patient-derived orthotopic xenograft (PDOX) model. Oncotarget. 2016;7:85929-36.

35. Murakami T, Li S, Han Q, et al. Recombinant methioninase effectively targets a Ewing's sarcoma in a patient-derived orthotopic xenograft (PDOX) nudemouse model. Oncotarget. 2017;8:35630-8.

36. Murakami T, Singh AS, Kiyuna T, et al. Effective molecular targeting of CDK4/ 6 and IGF-1R in a rare FUS-ERG fusion CDKN2A-deletion doxorubicinresistant Ewing's sarcoma patient-derived orthotopic xenograft (PDOX) nude-mouse model. Oncotarget. 2016;7:47556-64.

37. Hoffman RM. Patient derived mouse models of cancer. New York: Human Press; 2017.

38. Murakami T, DeLong J, Eilber FC, Zhao M, Zhang Y, Zhang N, Singh A, Russell T, Deng S, Reynoso J, Quan C, Hiroshima Y, Matsuyama R, Chishima T, Tanaka K, Bouvet M, Chawla S, Endo I, Hoffman RM. Tumor-targeting Salmonella typhimurium $\mathrm{A} 1-\mathrm{R}$ in combination with doxorubicin eradicate soft tissue sarcoma in a patient-derived orthotopic xenograft (PDOX) model. Oncotarget. 2016;7(11):12783-90.

39. Igarashi K, Kawaguchi K, Murakami T, et al. A novel anionic-phosphateplatinum complex effectively targets an undifferentiated pleomorphic sarcoma better than cisplatinum and doxorubicin in a patient-derived orthotopic xenograft (PDOX). Oncotarget. 2017;8:63353-9.

40. Igarashi K, Kawaguchi K, Kiyuna T, Miyake K, Miyake M, Li Y, Nelson SD, et al. Temozolomide combined with irinotecan regresses a cisplatinum-resistant relapsed osteosarcoma in a patient-derived orthotopic xenograft (PDOX) precision-oncology mouse model. Oncotarget. 2017;9(8):7774-81.

41. Igarashi K, Kawaguchi K, Murakami T, Kiyuna T, Miyake K, Nelson SD, Dry SM, Li Y, Yanagawa J, Russell TA, et al. Intra-arterial administration of tumortargeting Salmonella typhimurium A1-R regresses a cisplatin-resistant relapsed osteosarcoma in a patient-derived orthotopic xenograft (PDOX) mouse model. Cell Cycle. 2017;16(12):1164-70.

42. Igarashi K, Kawaguchi K, Murakami T, Kiyuna T, Miyake K, Singh AS, Nelson SD et al. High efficacy of Pazopanib on an undifferentiated spindle-cell sarcoma resistant to first-line therapy is identified with a patient-derived orthotopic xenograft (PDOX) nude mouse model. J Cell Biochem. 2017;118(9):2739-43.

43. Igarashi K, Kawaguchi K, Kiyuna T, et al. Tumor-targeting Salmonella typhimurium A1-R is a highly effective general therapeutic for undifferentiated soft tissue sarcoma patient-derived orthotopic xenograft nude-mouse models. Biochem Biophys Res Commun. 2018;497:1055-61.

44. Igarashi K, Kawaguchi K, Kiyuna T, Murakami T, Miwa S, Nelson SD, et al. Temozolomide combined with irinotecan caused regression in an adult pleomorphic rhabdomyosarcoma patient-derived orthotopic xenograft (PDOX) nude-mouse model. Oncotarget. 2017;8(44):75874-80.

45. Igarashi K, Kawaguchi K, Li S, et al. Recombinant methioninase in combination with doxorubicin (DOX) overcomes first-line DOX resistance in a patient-derived orthotopic xenograft nude-mouse model of undifferentiated spindle-cell sarcoma. Cancer Lett. 2018:417:168-73.

46. Hiroshima Y, Zhang Y, Zhang N, Uehara F, Maawy A, Murakami T, Mii S, Yamamoto M, Miwa S, et al. Patient-derived orthotopic xenograft (PDOX) nude mouse model of soft-tissue sarcoma more closely mimics the patient behavior in contrast to the subcutaneous ectopic model. Anticancer Res. 2015;35(2):697-701.

47. Kawaguchi K, Igarashi K, Murakami T, Kiyuna T, Nelson SD, Dry SM, et al. Combination of gemcitabine and docetaxel regresses both gastric leiomyosarcoma proliferation and invasion in an imageable patient-derived orthotopic xenograft (iPDOX) model. Cell Cycle. 2017;16(11):1063-9.

48. Kiyuna T, Murakami T, Tome $Y$, et al. High efficacy of tumor-targeting Salmonella typhimurium A1-R on a doxorubicin- and dactolisib-resistant follicular dendritic-cell sarcoma in a patient-derived orthotopic xenograft PDOX nude mouse model. Oncotarget. 2016;7:33046-54.

49. Miyake K, Murakami T, Kiyuna T, et al. The combination of temozolomideirinotecan regresses a doxorubicin-resistant patient-derived orthotopic xenograft (PDOX) nude-mouse model of recurrent Ewing's sarcoma with a FUS-ERG fusion and CDKN2A deletion: direction for third-line patient therapy. Oncotarget. 2017;8:103129-36.

50. Hoffman RM. Patient-derived orthotopic xenografts: better mimic of metastasis than subcutaneous xenografts. Nat Rev Cancer. 2015;15:451-2.

51. Hoffman RM. Patient-derived mouse models of Cancer. In: Coleman WB, Tsongalis GJ, editors. Molecular and Translational Medicine; 2017.

52. Pompili L, Porru M, Caruso C, Biroccio A, Leonetti C. Patient-derived xenografts: a relevant preclinical model for drug development. J Exp Clin Cancer Res. 2016;35(1):189.

53. Barone A, Chi DC, Theoret MR, Chen H, He K, Kufrin D, Helms WS, Subramaniam S, Zhao H, Patel A, Goldberg KB, Keegan P, Pazdur R. FDA approval summary: Trabectedin for Unresectable or metastatic Liposarcoma or Leiomyosarcoma following an Anthracycline-containing regimen. Clin Cancer Res. 2017:23(24):7448-53.

54. Demetri GD, von Mehren M, Jones RL, Hensley ML, Schuetze SM, et al. Efficacy and safety of Trabectedin or Dacarbazine for metastatic Liposarcoma or Leiomyosarcoma after failure of conventional chemotherapy: results of a phase III randomized multicenter clinical trial. J Clin Oncol. 2016;34(8):786-93.

55. Crago AM, Dickson MA. Liposarcoma: multimodality management and future targeted therapies. Surg Oncol Clin N Am. 2016;25(4):761-73.

56. Nakai T, Imura Y, Tamiya H, Yamada S, Nakai S, Yasuda N, Kaneko K, et al. Trabectedin is a promising antitumor agent potentially inducing melanocytic differentiation for clear cell sarcoma. Cancer Med. 2017;6(9):2121-30.

57. Hensley ML, Patel SR, von Mehren M, Ganjoo K, Jones RL, Staddon A, et al. Efficacy and safety of trabectedin or dacarbazine in patients with advanced uterine leiomyosarcoma after failure of anthracycline-based chemotherapy: subgroup analysis of a phase 3, randomized clinical trial. Gynecol Oncol. 2017;146(3):531-7.

58. McGovern Y, Zhou CD, Jones RL. Systemic therapy in metastatic or Unresectable well differentiated/dedifferentiated Liposarcoma. Front Oncol. 2017;7:292.

59. Spriano F, Chung EY, Panini N, Cascione L, Rinaldi A, Erba E, Stathis A, D'Incalci M, Bertoni F, Gatta R. Trabectedin is a novel chemotherapy agent for diffuse large B cell lymphoma. Br J Haematol. 2018; https://doi.org/10. 1111/bjh.15212.

60. Nteli VA, Knauf W, Janton-Klein A, El-Safadi S. Long-lasting response to Trabectedin in a patient with metastatic uterine Leiomyosarcoma: a case report. Case Rep Oncol. 2018;11(1):81-9.

61. Soares DG, Escargueil AE, Poindessous V, Sarasin A, de Gramont A, Bonatto D, Henriques JA, Larsen AK. Replication and homologous recombination repair regulate DNA double-strand break formation by the antitumor alkylator ecteinascidin 743. Proc. Natl. Acad. Sci. U S A. 2007:104(32):13062-7.

62. Larsen AK, Galmarini CM, D'Incalci M. Unique features of trabectedin mechanism of action. Cancer Chemother Pharmacol. 2016;77:663-71.

63. Schöffski P, Taron M, Jimeno J, Grosso F, Sanfilipio R, Casali PG, et al. Predictive impact of DNA repair functionality on clinical outcome of advanced sarcoma patients treated with trabectedin: a retrospective multicentric study. Eur J Cancer. 2011;47(7):1006-12.

64. Italiano A, Laurand A, Laroche A, Casali P, Sanfilippo R, Le Cesne A, et al. ERCC5/XPG, ERCC1, and BRCA1 gene status and clinical benefit of trabectedin in patients with soft tissue sarcoma. Cancer. 2011;117(15):3445-56.

65. Laroche-Clary A, Chaire V, Le Morvan V, Neuville A, Bertucci F, Salas S, Sanfilippo R, Pourquier P, Italiano A. BRCA1 haplotype and clinical benefit of trabectedin in soft-tissue sarcoma patients. Br J Cancer. 2015;112(4):688-92.

66. Angarita FA, Cannell AJ, Abdul Razak AR, Dickson BC, Blackstein ME. Trabectedin for inoperable or recurrent soft tissue sarcoma in adult patients: a retrospective cohort study. BMC Cancer. 2016;16:30.

67. Igarashi K, Murakami T, Kawaguchi K, Kiyuna T, Miyake K, Zhang Y, Nelson SD, Dry SM, Li Y, Yanagawa J, Russell TA, Singh AS, Tsuchiya H, Elliott I, Eilber FC, Hoffman RM. A patient-derived orthotopic xenograft (PDOX) mouse model of a cisplatinum-resistant osteosarcoma lung metastasis that was sensitive to temozolomide and trabectedin: implications for precision oncology. Oncotarget. 2017:8(37):62111-9.

68. Fu X, Niu W, Li J, Kiliti AJ, Al-Ahmadie HA, lyer G, Gao SP, Li Q. Activating mutation of PDGFRB gene in a rare cardiac undifferentiated intimal sarcoma of the left atrium: a case report. Oncotarget. 2017;8(46):81709-16. 
69. Miyake K, Murakami T, Tome Y, Igarashi K, et al. Doxorubicin-resistant pleomorphic liposarcoma with PDGFRA gene amplification is targeted and regressed by pazopanib in a patient-derived orthotopic xenograft mouse model. Tissue Cell. 2018:53:30-6.

70. Kawaguchi K, Igarashi K, Miyake K, et al. MEK inhibitor trametinib in combination with gemcitabine regresses a patient-derived orthotopic xenograft (PDOX) pancreatic cancer nude mouse model. Tissue Cell. 2018;52:124-8.

71. Igarashi K, Kawaguchi K, Kiyuna T, Miyake K, et al. Temozolomide regresses a doxorubicin-resistant undifferentiated spindle-cell sarcoma patient-derived orthotopic xenograft (PDOX): precision-oncology nude-mouse model matching the patient with effective therapy. J Cell Biochem. 2018; https://doi.org/10.1002/jcb.26792.

72. Jones RL, Fisher C, Al-Muderis O. Judson IR (2005) differential sensitivity of liposarcoma subtypes to chemotherapy. Eur J Cancer. 2005;41(18):2853-60.

73. Movva S, Verschraegen C. Systemic management strategies for metastatic soft tissue sarcoma. Drugs. 2011;71(16):2115-29.

74. Grosso F, Jones RL, Demetri GD, Judson IR, Blay JY, et al. Efficacy of trabectedin (ecteinascidin-743) in advanced pretreated myxoid liposarcomas: a retrospective study. Lancet Oncol. 2007;8(7):595-602.

75. Pignochino Y, Capozzi F, D'Ambrosio L, Dell'Aglio C, Basiricò M, et al. PARP1 expression drives the synergistic antitumor activity of trabectedin and PARP1 inhibitors in sarcoma preclinical models. Mol Cancer. 2017;16(1):86.

76. Laroche A, Chaire V, Le Loarer F, Algéo MP, Rey C, Tran K, Lucchesi C, Italiano A. Activity of trabectedin and the PARP inhibitor rucaparib in softtissue sarcomas. J Hematol Oncol. 2017;10(1):84.

77. Germano G, Frapolli R, Belgiovine C, Anselmo A, Pesce S, Liguori M, Erba E, Uboldi S, Zucchetti M, Pasqualini F, et al. Role of macrophage targeting in the antitumor activity of trabectedin. Cancer Cell. 2013;23:249-62.

78. Germano G, Frapolli R, Simone M, Tavecchio M, Erba E, Pesce S, Pasqualini F, Grosso F, Sanfilippo R, Casali PG, et al. Antitumor and anti-inflammatory effects of trabectedin on human myxoid liposarcoma cells. Cancer Res. 2010;70:2235-44.

79. Ratti C, Botti L, Cancila V, Galvan S, Torselli I, Garofalo C, et al. Trabectedin overrides osteosarcoma Differentiative block and reprograms the tumor immune environment enabling effective combination with immune checkpoint inhibitors. Clin Cancer Res. 2017;23(17):5149-61.

80. Gronchi A, Bui BN, Bonvalot S, Pilotti S, Ferrari S, Hohenberger P, et al. Phase II clinical trial of neoadjuvant trabectedin in patients with advanced localized myxoid liposarcoma. Ann Oncol. 2012;23(3):771-6.

81. De Sanctis R, Marrari A, Marchetti S, Mussi C, Balzarini L, et al. Efficacy of trabectedin in advanced soft tissue sarcoma: beyond lipo- and leiomyosarcoma drug des. Devel Ther. 2015;9:5785-91.

82. Khalifa J, Ouali M, Chaltiel L, Le Guellec S, Le Cesne A, Blay JY, et al. Efficacy of trabectedin in malignant solitary fibrous tumors: a retrospective analysis from the French sarcoma group. BMC Cancer. 2015;15:700.

83. Bui-Nguyen B, Butrynski JE, Penel N, Blay JY, Isambert N, Milhem M, Kerst JM, Reyners AK, Litière S, Marréaud S, Collin F, van der Graaf WT, European Organisation for Research and Treatment of Cancer Soft Tissue and Bone Sarcoma Group (EORTC/STBSG) and the Sarcoma Alliance for Research through Collaboration (SARC). A phase Ilb multicentre study comparing the efficacy of trabectedin to doxorubicin in patients with advanced or metastatic untreated soft tissue sarcoma: the TRUSTS trial. Eur. J. Cancer. 2015;51(10):1312-20

84. Nakamura T, Matsumine A, Sudo A. The value of trabectedin in the treatment of soft tissue sarcoma. Ther Clin Risk Manag. 2016;12:73-9.

85. Buonadonna A, Benson C, Casanova J, Kasper B, López Pousa A, Mazzeo F, Brodowicz T, Penel N. A noninterventional, multicenter, prospective phase IV study of trabectedin in patients with advanced soft tissue sarcoma. AntiCancer Drugs. 2017;28(10):1157-65.

86. Takahashi M, Takahashi S, Araki N, Sugiura H, Ueda T, Yonemoto T, et al. Efficacy of Trabectedin in patients with advanced translocationrelated sarcomas: pooled analysis of two phase II studies. Oncologist. 2017;22(8):979-88

87. Adam JP, Boumedien F, Letarte N, Provencher D. Single agent trabectedin in heavily pretreated patients with recurrent ovarian cancer. Gynecol Oncol. 2017;147(1):47-53.

88. Ghouadni A, Delaloge S, Lardelli P, Kahatt C, Byrski T, Blum JL, et al. Higher antitumor activity of trabectedin in germline BRCA2 carriers with advanced breast cancer as compared to BRCA1 carriers: a subset analysis of a dedicated phase II trial. Breast. 2017;34:18-23.
89. Stacchiotti S, Saponara M, Frapolli R, Tortoreto M, Cominetti D, et al. Patientderived solitary fibrous tumour xenografts predict high sensitivity to doxorubicin/dacarbazine combination confirmed in the clinic and highlight the potential effectiveness of trabectedin or eribulin against this tumour. Eur J Cancer. 2017;76:84-92.

90. Uboldi S, Craparotta I, Colella G, Ronchetti E, Beltrame L, et al. Mechanism of action of trabectedin in desmoplastic small round cell tumor cells. BMC Cancer. 2017;17(1):107.

91. Romano M, Della Porta MG, Gallì A, Panini N, Licandro SA, et al. Antitumour activity of trabectedin in myelodysplastic/myeloproliferative neoplasms. Br J Cancer. 2017:116(3):335-43.

\section{Ready to submit your research? Choose BMC and benefit from:}

- fast, convenient online submission

- thorough peer review by experienced researchers in your field

- rapid publication on acceptance

- support for research data, including large and complex data types

- gold Open Access which fosters wider collaboration and increased citations

- maximum visibility for your research: over $100 \mathrm{M}$ website views per year

At BMC, research is always in progress.

Learn more biomedcentral.com/submissions 